\title{
Do íntimo ao compartilhado: fotoperformance como meio de tocar na ferida
}

From intimate to shared:

photoperformance as a means of touching the wound

De lo íntimo a lo compartido: fotoperformance como medio de tocar la herida 


\section{Resumo}

A fotoperformance intitulada Rotina é composta por 8 fotografias que exploram a performatividade dentro de um tema contemporâneo: a ansiedade. Corpo, fotografia e pós-produção digital se mesclam para dar origem à fotoperformance.

Palavras-chave: Corpo; Fotoperformance; Fotografia; Ansiedade.

\section{Abstract}

The photoperformance entitled Routine is composed of 8 photographs that explore performativity within a contemporary theme: anxiety. Body, photography and digital post production merge to give rise to the photoperformance.

Keywords: Body; Photoperformance; Photography, Anxiety.

\section{Resumen}

El fotoperformance titulado Rutina se compone de 8 fotografías que exploran la performatividad dentro de un tema contemporáneo: la ansiedad. El cuerpo, la fotografía y la postproducción digital se unen para dar lugar el fotoperformance.

Palabras clave: Cuerpo; Fotoperformance; Fotografía; Ansiedad. 
A fotoperformance Rotina foi realizada em 2019 pela fotógrafa e arte-educadora cearense Tatiana Tavares, sendo composta por 8 fotos em preto e branco. Após as fotografias serem realizadas, as imagens passaram pelo processo de pós-produção no Adobe Photoshop, sendo feita uma sobreposição em cada imagem com uma combinação de duas fotos existentes ou mais para dar origem a uma única foto.

Rotina foi pensada pela a artista a partir de um convite da Feira do Oriente (2019) para a exposição em coletivo intitulada: Sol para mulheres, que ocorreu em dezembro de 2019 na Galeria Aymoré no Rio de Janeiro, tendo na curadoria, Cecília Bedê, Patrícia Veloso e Waléria Américo. A exposição foi formada por fotógrafas e artistas visuais do Ceará, todas participantes do programa Sol para mulheres, que acorre em Fortaleza na Imagem Brasil Galeria com o objetivo de valorizar e divulgar o trabalho de produtoras de imagem no Ceará, através de formações de grupos de estudos teóricos e práticos, voluntariamente. A exposição foi realizada com imagens impressas de tamanhos variados, de acordo com a necessidade de cada imagem.

Para além da exposição, Rotina deu início a um projeto ainda em andamento, chamado Diário Visual, trata-se de uma série de fotoperformances com temas autobiográficos. É uma volta da artista para dentro de si com questões pertinentes a sua história de vida, fotoperformances que possuem uma linha narrativa e que podem se interligar.

Em Rotina, o objetivo é apresentar a ansiedade vivida pela a artista, mais precisamente, a relação de dependência que se estabelece com o uso de remédios para controle da ansiedade. O título da obra faz alusão a algo que é do dia a dia. Convivendo durante muito tempo com a ansiedade e sendo uma jornada muito difícil até conseguir trazê-la para o campo da arte, não há uma metodologia correta a se seguir, pois trata-se de um assunto complexo e íntimo. Logo, crê que ao falar do assunto através da arte, possibilita encarar com outro viés o seu transtorno.

Algumas artistas transitam para uma voz ativa em suas obras, ou seja, fazer de algo ruim ocorrido na vida de forma passiva, algo ativamente experimentado. Dentre elas, um exemplo a ser citado é Louise Bourgeois (1911-2010), artista plástica francesa conhecida principalmente pelo seu trabalho Maman (1999). Ela mostra em suas obras, que não existe uma separação entre vida e obra, suas emoções, suas experiências de vida (muitas da infância) são a matéria-prima para a construção de seus trabalhos. Louise também atribui a criação artística um valor terapêutico, pois "leva às últimas consequências o poder que a escultura teria de eliminação das ansiedades sentidas pela artista." (RIVERA, 2002, p. 62). Outros exemplos de artistas que levam como eixo central dos seus trabalhos temas da sua vida é por exemplo, a pintora mexicana Frida Kahlo (1907-1954), fazendo da sua arte propriamente uma arte autobiográfica, os temas perpassam desde relacionamentos a acidentes e abortos. $O$ seu eu era o tema que mais conhecia. Dentre as inúmeras pinturas, podemos destacar A coluna partida, de 1944, um autorretrato pintado logo após Frida passar por uma cirurgia na coluna vertebral. $O$ último exemplo apresentado, é a artista nascida na Sérvia, muito conhecida por suas performances, Marina Abramovic (1946- ), onde muitas temáticas de seus trabalhos passam por questionamentos e situações de sua 
vida pessoal, como a famosa performance Rest Energy, de 1980, realizada em dupla, junto ao seu companheiro na época Ulay (1943-2020). Esse trabalho dependia da relação de confiança que havia entre o casal de artistas (um fica frente ao outro, Marina segura o arco e Ulay com a flecha nas mãos, apontado para o coração de Marina). Inspirada nas artistas mencionadas, Rotina tem como matéria-prima um assunto pessoal, a vida e obra em simbiose, mesmo tomando partida de um transtorno vivido de forma íntima pela artista através da performatividade, o tema se expande. O assunto é transferido para a imagem e como consequência alcança o público que interpreta e dialoga, formando novos ciclos e conexões que saem da esfera individual e percorre o social. Nesses momentos, podemos perceber o quanto um assunto pessoal pode ser uma característica da contemporaneidade e afeta de maneira muito recorrente boa parte dos indivíduos. Às vezes ao tocar na sua ferida, acaba por fazer com que os outros também sintam a dor.

Transtornos mentais, como a ansiedade, é um somatório de diversas influências sociais,

Todo investimento disciplinador no corpo para ajustá-lo ao ritmo das fábricas, escolas, quartéis, prisões, toda a ação positivo-material do poder em adestrar $\circ$ gesto, regulamentar o comportamento, normalizar o prazer e interpretar o discurso produziram a consciência do sujeito em relação ao próprio corpo, mas também a inevitável emergência do contra efeito de reivindicação por seu domínio: a saúde contra a economia, principalmente, o prazer contra as normas morais da sexualidade, do casamento, do pudor. (BARROS, 2016, p. 116).

A ansiedade da artista não tem um único gatilho, são suas experiências desde a infância que moldaram o seu eu de hoje. O núcleo familiar, a rua, o trabalho, tudo influencia e reverbera para a sua formação da personalidade e do comportamento. Para a mulher, a vida social é mais difícil, e isso pode acabar por reprimi-la, assim muitos transtornos acabam por surgir e a ansiedade se encontra entre eles.

Diversas artistas brasileiras discutiram temas que nos são importantes em diversos núcleos e são pautas que a arte majoritariamente formada por homens não consegue adentrar, como a artista plástica ítalo-brasileira Anna Maria Maiolino (1942- ) com a sua obra Arroz e Feijão, uma instalação de 1979, em que também fala "acerca do papel que o código da comida e seus desdobramentos morais desempenham para situar a mulher e o feminino no seu sentido mais tradicional." (BARROS, 2016, p. 34). Márcia X (1959-2005), artista plástica brasileira, na sua performance Pancake (2001) que evoca questões da sexualidade da mulher. Roberta Barros, artista e pesquisadora brasileira (ano de nascimento não encontrado-) com seu Projeto Costurar (2005), que consiste em retirar de seus locais de comercialização, revistas ditas para o público feminino com foco na beleza para transformar suas identidades como objeto. "Com fio cirúrgico, faço uma plástica na imagem da capa. (...) Aqui, a revista é objeto que se presta à manipulação, bem como as atrizes ou modelos exibidas em suas páginas, que tiveram os traços e as marcas de seus corpos eliminados." (BARROS, 2016, p. 102). 
Especialmente no contexto atual, no virar de 2020 para 2021, torna-se necessário percebemos com cada vez mais frequência temas intitulados feministas (ou não) vinculados a transtornos mentais, mesmo sendo um tema íntimo, infelizmente, ele é comum, pois já faz parte do cotidiano de uma parcela grande da sociedade em maior ou menor grau.

A fotoperformance não tem a intenção de ser uma cópia fiel do cotidiano. A sobreposição de imagens cria diversas camadas, o que acaba por estabelecer essas variadas camadas para o discurso e suas múltiplas interpretações. Apesar do tema ser bastante vivo e do dia a dia, optou-se por aproximá-lo esteticamente do surreal. Talvez seja um subterfúgio para deixar o transtorno mais leve? Ser digerido mais fácil pela artista? Ainda não há respostas e certezas. O processo foi manipulado na pós- produção, não possuindo uma relação extremamente estreita com a realidade (não é uma fotografia do seu dia, se aproximando talvez mais de uma ilustração de um sentimento), pois foi realizado um trabalho planejado para a câmera. Eis a dualidade da artista em apresentar algo do seu cotidiano, que é muito presente, mas uma "farsa" ao mesmo tempo. Ali nem é seu quarto de verdade. A relação entre real e fictício é muito tênue quando falamos de fotografia. Seria menos sincero a fotoperformance quando sabemos desses detalhes? E quando sabemos do estudo, da montagem e todo o processo de realização? Tratar de um transtorno deve ser simplista? Para a artista, assim como há uma complexidade em conviver e buscar tratamento, na arte não poderia ser diferente.

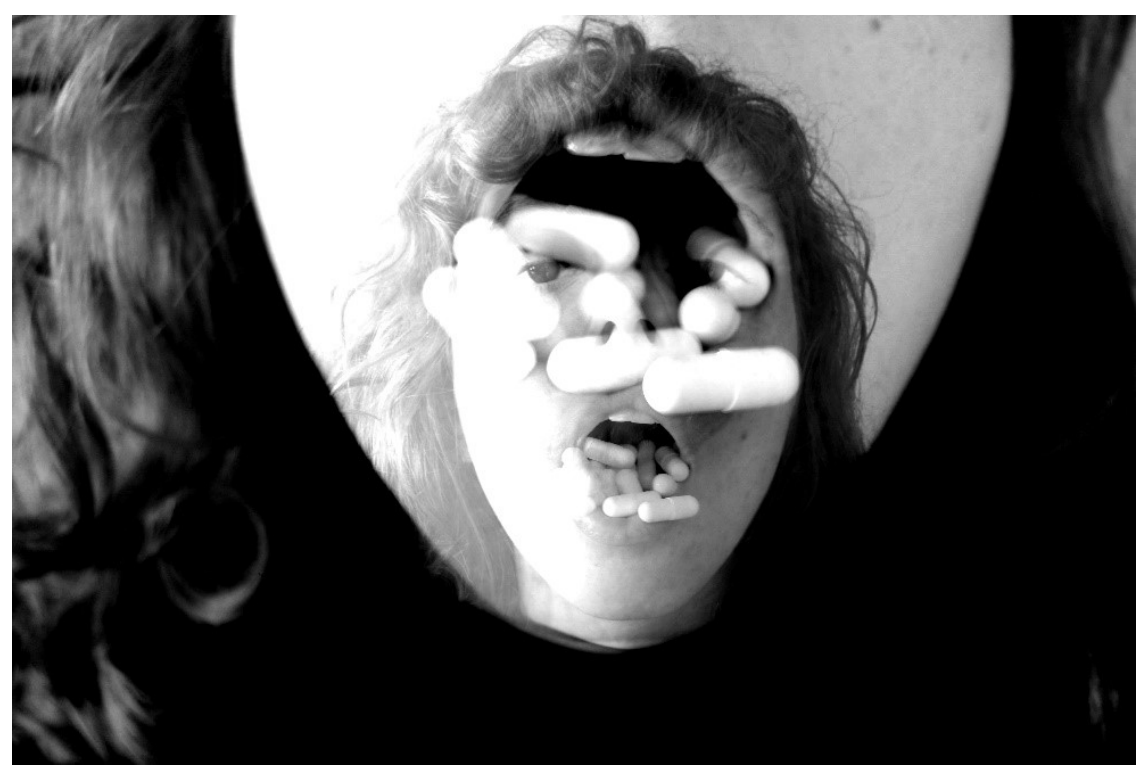

Figura 1. Tatiana Tavares. Fotoperformance Rotina. Fotografia digital com sobreposição de imagem no Adobe Photoshop. 2019. 


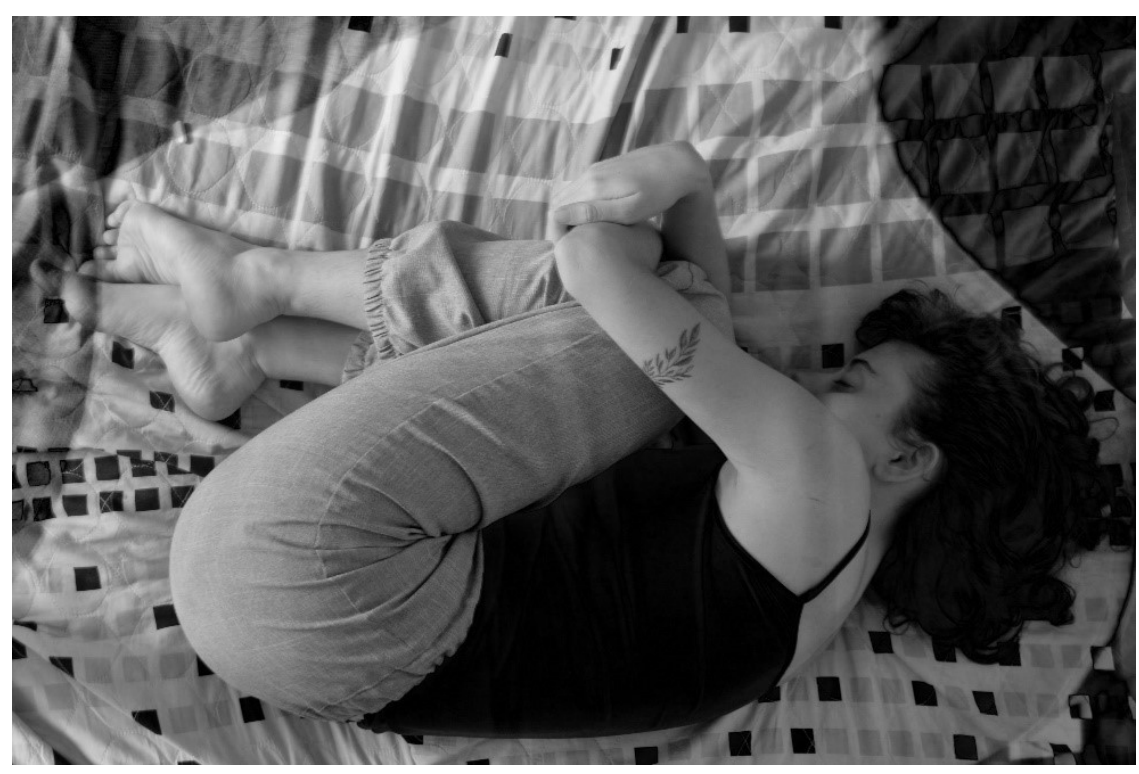

Figura 2. Tatiana Tavares. Fotoperformance Rotina. Fotografia digital com sobreposição de imagem no Adobe Photoshop. 2019.

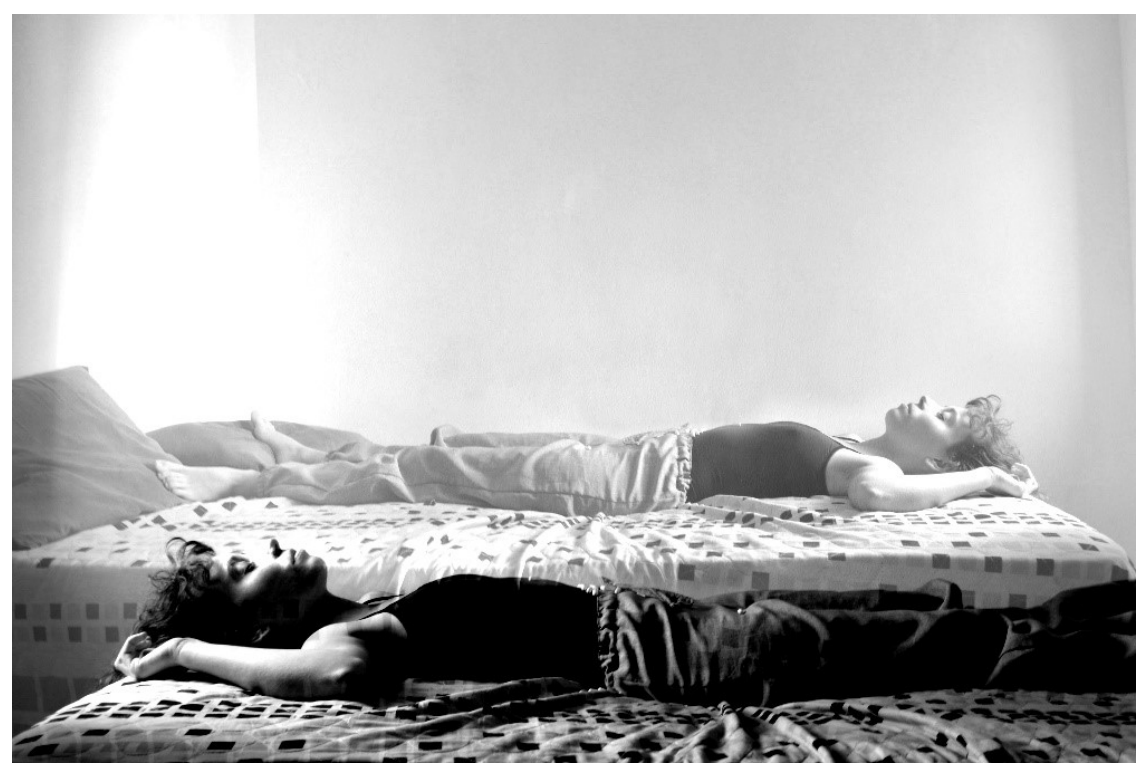

Figura 3. Tatiana Tavares. Fotoperformance Rotina. Fotografia digital com sobreposição de imagem no Adobe Photoshop. 2019. 


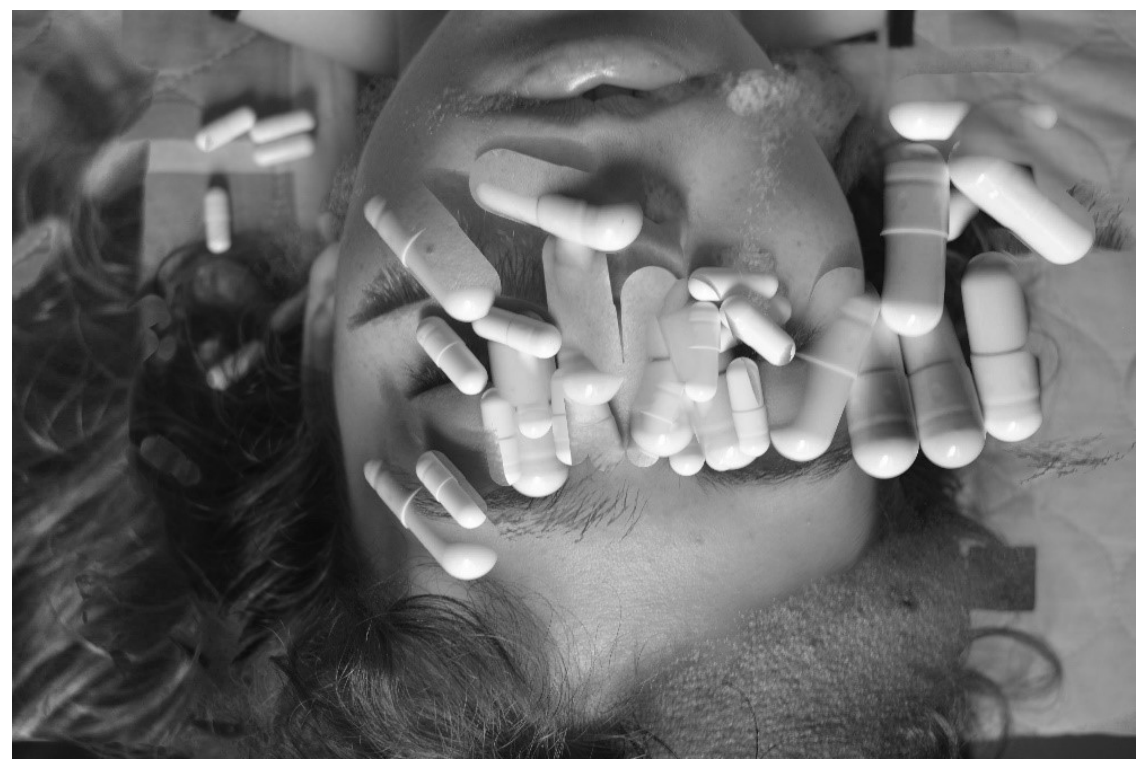

Figura 4. Tatiana Tavares. Fotoperformance Rotina. Fotografia digital com sobreposição de imagem no Adobe Photoshop. 2019.

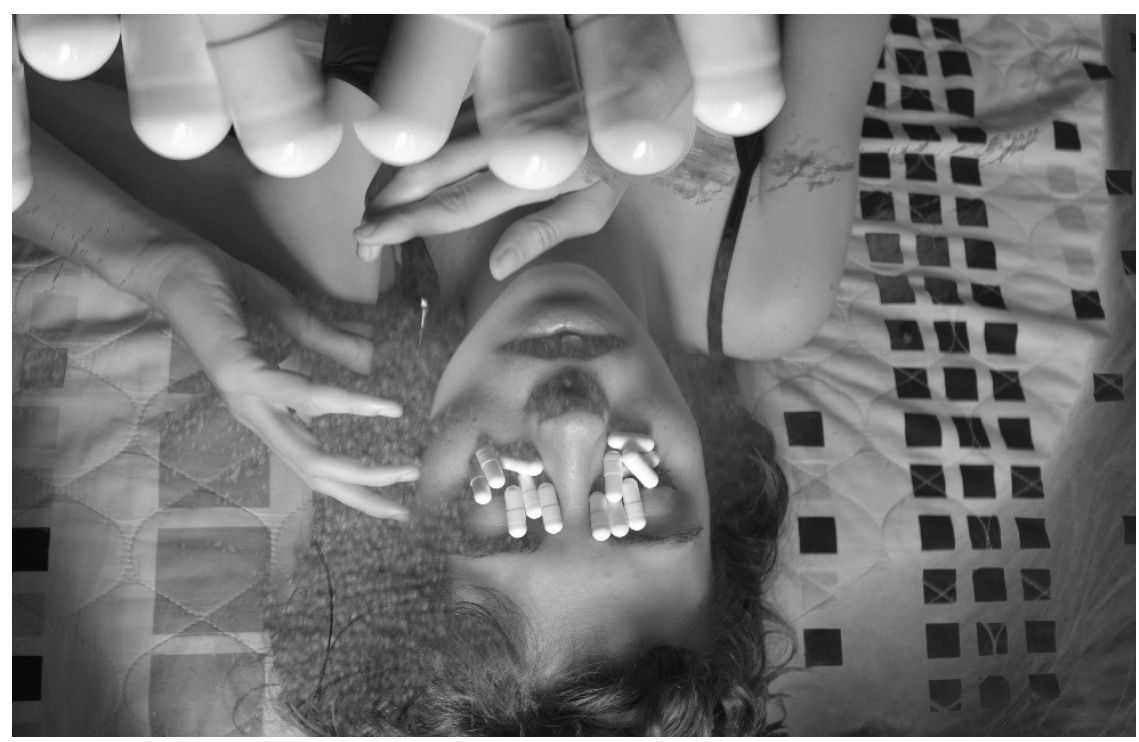

Figura 5. Tatiana Tavares. Fotoperformance Rotina. Fotografia digital com sobreposição de imagem no Adobe Photoshop. 2019. 


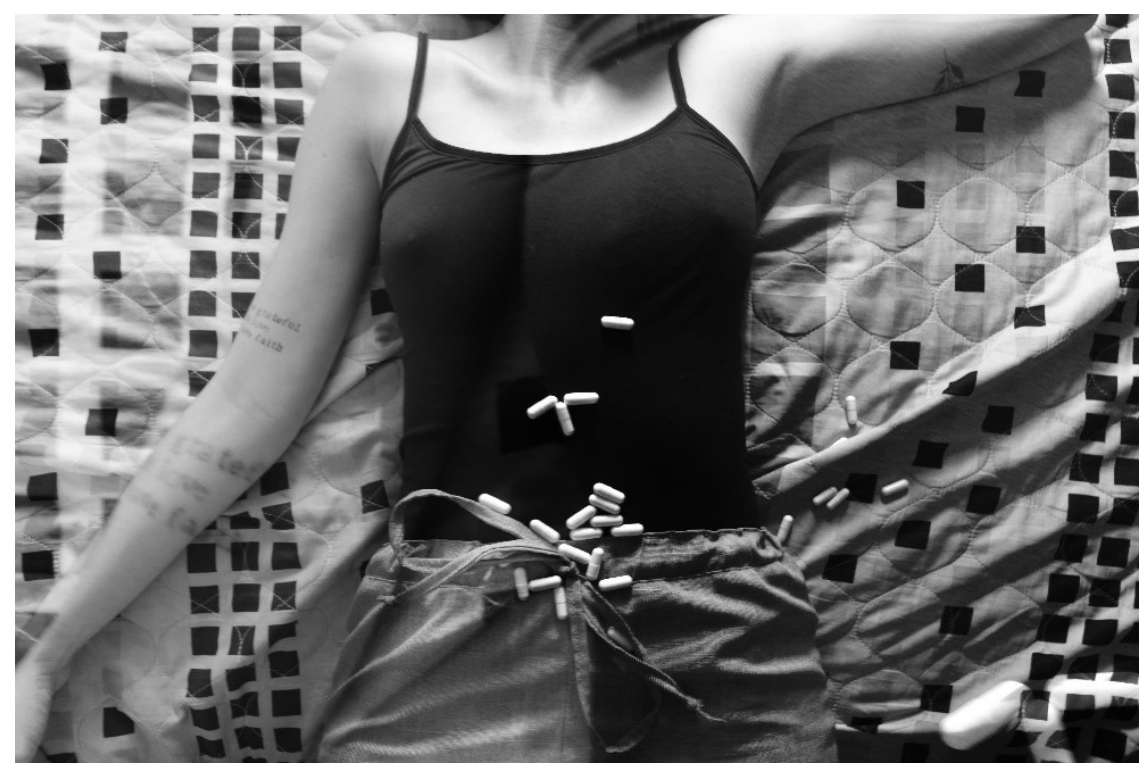

Figura 6. Tatiana Tavares. Fotoperformance Rotina. Fotografia digital com sobreposição de imagem no Adobe Photoshop. 2019.

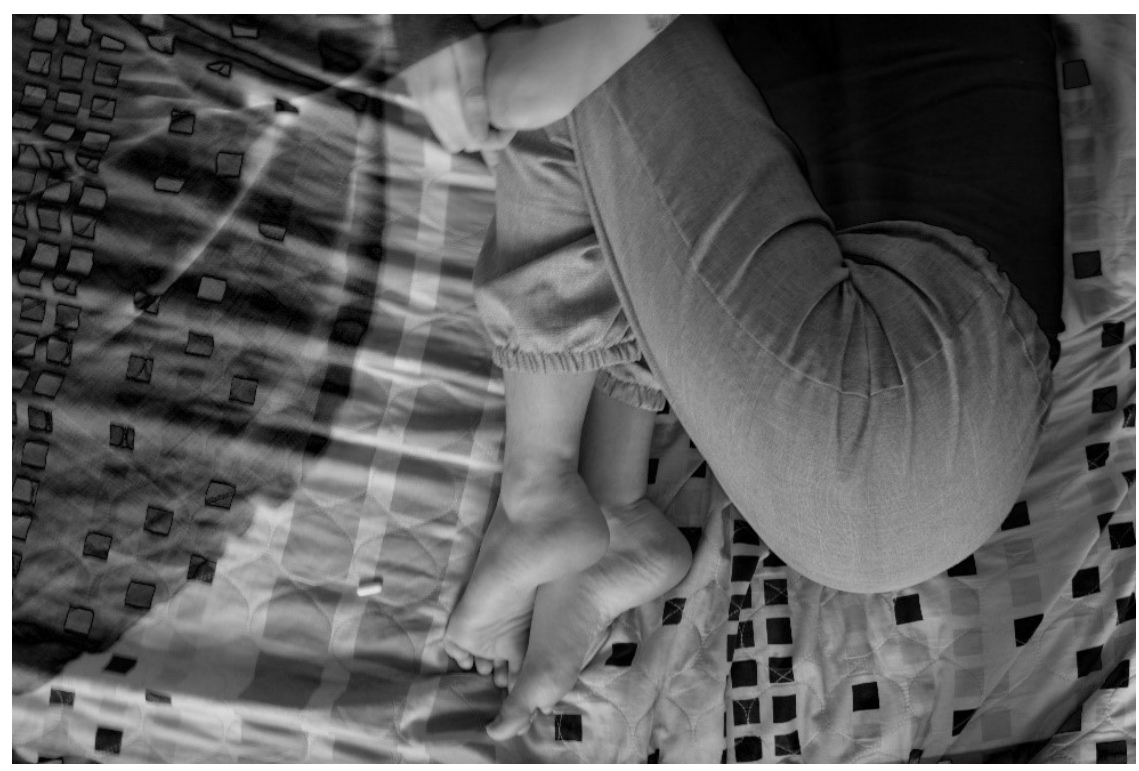

Figura 7. Tatiana Tavares. Fotoperformance Rotina. Fotografia digital com sobreposição de imagem no Adobe Photoshop. 2019. 


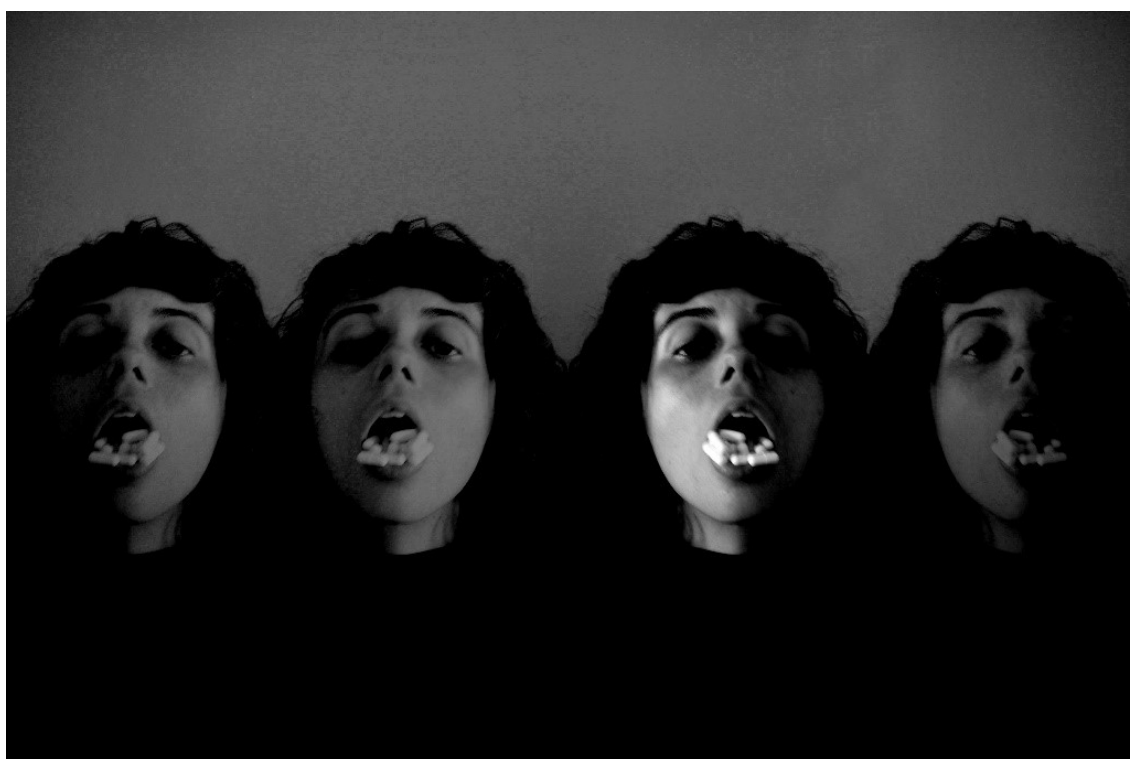

Figura 8. Tatiana Tavares. Fotoperformance Rotina. Fotografia digital com sobreposição de imagem no Adobe Photoshop. 2019. 


\section{Referências}

BARROS, R. Elogio ao toque. 1. ed. Rio de Janeiro, RJ: Relacionarte, 2016. 288 p.

RIVERA, T. Arte e psicanálise. 2 ed. Rio de Janeiro, RJ: Jorge Zahar, 2002. 74 p.

Submetido em 05/01/2020

Aprovado em 27/07/2021 